\title{
Removal of Residual Aluminium-Dye Complex and Aluminium Ion from Spent Natural-Dye Solution Using Activated Carbons
}

\author{
Malee Tangsathitkulchai ${ }^{1}$, Chaiyot Tangsathitkulchai ${ }^{2, *}$, Kamonchanok Wongsooksin ${ }^{3}$, \\ and Saowanee Chuyingsakuntip ${ }^{2}$ \\ 1 School of Chemistry, Suranaree University of Technology, Muang District, Nakhon Ratchasima 30000, \\ Thailand \\ 2 School of Chemical Engineering, Suranaree University of Technology, Muang District, Nakhon \\ Ratchasima 30000, Thailand \\ 3 Faculty of Science and Technology, Nakhon Ratchasima Rajabhat University, Nakhon Ratchasima 30000, \\ Thailand \\ *E-mail: chaiyot@sut.ac.th
}

\begin{abstract}
The crude dye extracted from the heartwood of Ceasalpinia sappan Linn. was reacted with alum to form a solution containing a cationic dye complex of [Al(brazilein) $\left.{ }_{2}\right]^{+}$and used for the dyeing of silk yarn. The dye solution left after dyeing was treated with coconut shell activated carbons with different pore structure and surface chemistry to remove the dye complex and with eucalyptus-based activated carbon to remove the residual aluminium ion $\left(\mathrm{Al}^{3+}\right)$. Adsorption kinetics of this dye complex was well described by the pseudo-second order model and the time to reach equilibrium was relatively long, suggesting the intra-particle diffusion to be the controlling step. Isotherm data for dye adsorption of all tested carbons could be well fitted by the well-known Langmuir equation. Activated carbon containing mainly micropores was not effective in adsorbing the relatively large size of dye molecules. However, after oxidizing the carbon surface with $\mathrm{HNO}_{3}$ to fix the oxygen surface functional groups, the adsorption was enhanced significantly by electrostatic attraction. Porous activated carbon constituting larger proportion of mesopores gave higher adsorption capacity than that of microporous carbon with the dispersive-force attraction being the dominant adsorption mechanism. The adsorption of $\mathrm{Al}^{3+}$ by eucalyptus activated carbon followed the linear isotherm equation with Henry's constant of $0.74 \mathrm{~L} / \mathrm{mg}$ and about $80 \%$ removal of the initial $\mathrm{Al}^{3+}$ content $(8.2 \mathrm{mg} / \mathrm{L})$ could be achieved using a typical carbon dosage of around $6 \mathrm{~g}$ carbon/L of dye solution.
\end{abstract}

Keywords: Activated carbon, adsorption, aluminium-dye complex, dyeing process.

ENGINEERING JOURNAL Volume 16 Issue 5

Received 15 May 2012

Accepted 3 July 2012

Published 1 October 2012

Online at http:/ /www.engj.org/

DOI:10.4186/ej.2012.16.5.29 


\section{Introduction}

The aqueous extract from the heartwood of Ceasalpinia. Sappan Linn. is generally used for the dyeing of silk, especially in the northeast area of Thailand. The extracted dye, which are mainly composed of brazilin and brazilein (see Fig. 1), gives a beautiful red or pink color to the silk. However, this natural dye has poor fastness property. To overcome this problem, some metal ion-based mordants have been used $[1,2]$. One such mordant commonly used is alum, which provides a source of aluminium ions. Wongsooksin et al. [3] reported that with alum added, the dye presented in the form of $\left[\mathrm{Al}(\text { brazilein })_{2}\right]^{+}$complex, considered as a cationic dye as shown in Fig. 1(c). However, the problem concerning silk dyeing is the release of residual aluminium ion and coloration of the effluent generated from wastage and washing during the process of silk dyeing. Aluminium is a potential hazard connecting to Alzheimer's disease in human being and it is allowed to have only 0.05 to $0.2 \mathrm{mg} / \mathrm{L}$ in drinking water according to standard environmental regulations [4]. For coloration, complete dye removal is necessary because dyes will be visible even if present at a low concentration.

Although there are several wastewater treatment methods available, there is virtually no single process capable of adequate treatment for different types of dyeing effluents. Adsorption is an effective separation process and activated carbon is the most widely used adsorbent for removing a variety of pollutant species from wastewater, particularly metal ions, organic compounds and dyes [5-8]. Apart from suitable pore size distribution, the surface chemistry of activated carbon is another factor that may improve or hinder its ability to adsorb certain species [9-11]. The surface chemistry of activated carbon is related to the presence of surface functional groups, especially oxygen functional groups usually locating at the edges of graphene layers. In addition to oxygen acidic surface groups such as carboxylic acid, lactonic and phenolic groups, the carbon surface is known to have some basic functional groups e.g., ketone and carbonyl groups. Many researchers have reported that the oxidized activated carbon could enhance the adsorption of different aqueous metal ions as well as cationic and aniline dyes [12-14]. On the other hand, the oxygen-free activated carbon with a suitable porosity was used to adsorb anionic dyes where the adsorption was generally determined by $\pi-\pi$ dispersion interaction between the surface electron of activated carbon and the aromatic ring of the adsorbates[15,16].

In the present study, a coconut shell activated carbons prepared by steam activation and chemical activation were chosen as potential adsorbents for the adsorption of the residual $\left[\mathrm{Al}(\mathrm{brazilien})_{2}\right]^{+}$from real silk-dyeing effluent. The activated carbon was also modified using nitric acid and thermal treatment in order to change its surface chemistry. An activated carbon prepared from eucalyptus wood by physical activation with carbon dioxide was also used to study the adsorption of the above-mentioned cationic dye as well as the aluminium ion remaining in the spent natural-dye solution.

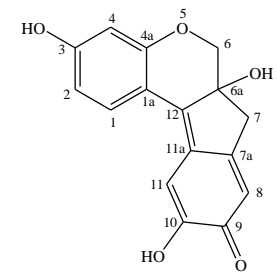

(a)

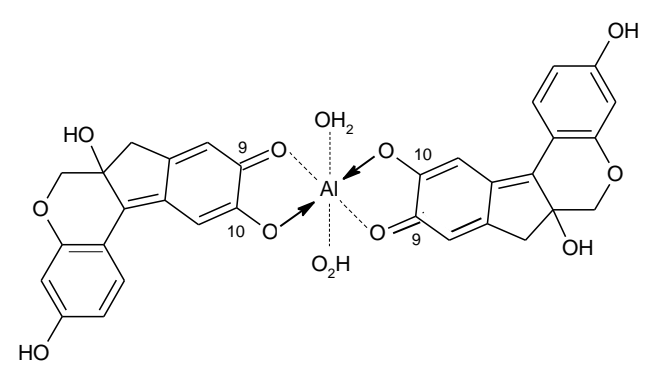

(c)

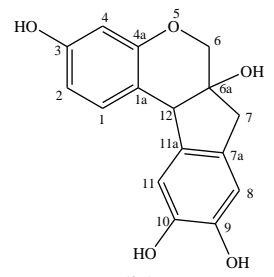

(b)

Fig. 1. Chemical structure of (a) brazilein, (b) brazilin, and (c) $\left[\mathrm{Al}(\text { brazilein) }]^{+}\right.$dye complex. 


\section{Experimental}

\subsection{Activated Carbon Preparation}

Activated carbons from two types of precursors, namely coconut shell and eucalyptus wood(Eucalyptus camaldulensis Dehn.) were used in this study. The coconut shell based activated carbon prepared by physical activation with steam (1.8 mm average size) was supplied by C. Gigantic Company (Nakhon Ratchasima, Thailand) and was designated as sample C. The chemically activated carbon from coconut shell (sample CZ) was prepared in this study by using the procedure suggested by Hu et al. [17] to produce carbon with larger proportion of mesopores, as follows. The dried coconut shell (average screen size of $1.67 \mathrm{~mm}$ ) was impregnated with saturated $\mathrm{ZnCl}_{2}$ solution, using $\mathrm{ZnCl}_{2}$ to coconut shell weight ratio of 3:1. The impregnated sample was dried in an oven at $110^{\circ} \mathrm{C}$ for 24 hours. The dried sample was then carbonized under nitrogen in a tube furnace (Carbolite, UK) at $800^{\circ} \mathrm{C}$ for 1 hour, after that the inert gas was switched to carbon dioxide and kept for another hour and cooled down to room temperature under the constant flow of nitrogen. The resulting carbon was washed several times with hot water until the rinsing water was free from zinc and chloride ions, as checked by adding $\mathrm{AgNO}_{3}$ solution and no white precipitate was formed. The washed product was finally dried at $110^{\circ} \mathrm{C}$ overnight.

An activated carbon sample was also prepared from eucalyptus wood $(0.714 \mathrm{~mm}$ average size) by carbonizing the precursor in a tube furnace under the flow of nitrogen gas at $400^{\circ} \mathrm{C}$ for 1 hour, followed by activating the resulting char with carbon dioxide in the same furnace at $800^{\circ} \mathrm{C}$ for 2 hours. The obtained carbon sample was designated as sample W.

\subsection{Liquid-phase Oxidation}

The oxidizing agent used for the liquid-phase oxidation in order to incorporate oxygen functional groups onto physically and chemically activated carbons (sample C and CZ) was 7.5M nitric acid solution. Separate samples of physically activated carbon (one gram each) were refluxed at solution boiling temperatures (80$90^{\circ} \mathrm{C}$ ) for $1,2,4,8,16,24$, and 48 hours with the designated sample codes given as C1, C2, C4, C8, C16, C24 and C48, respectively. The chemically activated carbon (sample CZ) was refluxed under the same condition as that of sample C4, and given sample code as CZ4.

\subsection{Heat Treatment of Oxidized Carbon}

Five grams of the oxidized carbon (sample C4) was subjected to heat treatment in a packed bed reactor at two temperatures of 700 and $900^{\circ} \mathrm{C}$ under the constant flow of $\mathrm{N}_{2}$ at $100 \mathrm{~cm}^{3} / \mathrm{min}$ for 10 hours. The heat treated samples were designated as C4-700 and C4-900, respectively.

\subsection{Characterization of Activated Carbons}

The original activated carbons, the oxidized activated carbons and the heat treated carbons were characterized for the following : the acidic group contents on the carbon surface using Boehm titration, $\mathrm{pH}$ at the point of zero charge $\left(\mathrm{pH}_{\mathrm{pzc}}\right)$ to assess the extent of surface acidity and $\mathrm{N}_{2}$ adsorption isotherms to determine the adsorbent porous properties. Details of experimental measurements and calculation of these methods are given elsewhere [18].

\subsection{Preparation of Natural Dye Extract and Al-dye Complex}

The heartwood of Ceasalpinia sapann Linn. was obtained from plantation area in Nakhon Ratchasima province, Thailand. The dried heartwood (200 grams) was chopped into small size $(0.3 \mathrm{~cm} \times 3 \mathrm{~cm})$ and extracted with boiling deionized water $(2 \mathrm{~L})$ using the ratio of 1 gram of wood per $10 \mathrm{~mL}$ of water for one hour at $80-95^{\circ} \mathrm{C}$. The aqueous extract was filtered and concentrated using a vacuum rotary evaporator (model R-210, Buchi). Then, it was dried in a vacuum freeze dryer (DW 3 Drywinner, Heto), giving the extract in powder form with $13 \%$ yield by weight.

The simultaneous-mordanting technique was used for the dyeing of silk in this study. Alum-dye stock solution (2:1 molar ratio) for dyeing silk yarn was prepared by mixing stock solutions of prepared dye powder $\left(5 \times 10^{-4} \mathrm{M}\right)$ and alum $\left[\mathrm{KAl}\left(\mathrm{SO}_{4}\right) 12 . \mathrm{H}_{2} \mathrm{O}\right]\left(5 \times 10^{-4} \mathrm{M}\right)$. This dye was present in the dye bath as a 
cationic complex $\left[\mathrm{Al}(\text { brazilein })_{2}\right]^{+}$or $\left[\mathrm{Al}\left(\mathrm{C}_{16} \mathrm{H}_{14} \mathrm{O}_{5}\right)_{2}\right]^{+}$which has a molar mass of $599 \mathrm{~g} / \mathrm{mol}$ [3]. After dyeing onto silk, the residual dye solution was diluted to have initial concentration of $220 \mathrm{mg} / \mathrm{L}$ which was simply called dye solution and kept for subsequent adsorption experiments.

\subsection{Adsorption Studies}

Tests were carried out to study the adsorption kinetics, the effect of solution $\mathrm{pH}$ and carbon dosage on the adsorption of Al-dye complex. For the study of adsorption equilibrium, $25 \mathrm{~mL}$ of dye solution was mixed with varying amounts of activated carbon. Each suspension mixture was shaken in a thermostat shaking bath at $30^{\circ} \mathrm{C}$ until the equilibrium was reached. The equilibrium concentration of the dye solution was determined from a prepared calibration curve based on measured absorbance using a UV-visible spectrophotometer (model 8453, Agilent) set at a wavelength $\left(\lambda_{\max }\right)$ of $509 \mathrm{~nm}$. The amount of dye adsorbed at equilibrium, $\mathrm{qe}(\mathrm{mg} / \mathrm{g}$ carbon), was obtained by a mass balance according to the equation,

$$
q_{e}=\left(C_{o}-C_{e}\right) V / W
$$

where $C_{o}(\mathrm{mg} / \mathrm{L})$ and $C_{e}(\mathrm{mg} / \mathrm{L})$ are the concentrations of dye complex in the solution at time $\mathrm{t}=0$ and at equilibrium time, respectively, $V$ is the volume of the solution $(\mathrm{L})$, and $W$ is the weight of activated carbon (g) used.

The adsorption of Al-dye complex and aluminium ion from dye solution by eucalyptus based activated carbon was also performed using the same procedure as that for coconut-shell based activated carbon. The total alumimium content in the solution at equilibrium (both in the dye complex and as aluminium ion) was analyzed by an Inductively Coupled Plasma-Mass Spectrometry (ICP-MS) instrument (7500 Series, Agilent).

\section{Results and Discussion}

\subsection{Porous and Surface Chemical Properties}

Table 1 shows the porous properties and $\mathrm{pH}$ PzC of all carbon samples studied in this work. For all the original activated carbons, the order of increasing surface area and pore volume is: $\mathrm{W}<\mathrm{C}<\mathrm{CZ}$. However, physically activated carbon from wood (sample W) gave the largest proportion of mesopore volume (31\%). For coconut shell activated carbons, the chemically activated carbon (sample CZ) constituted more mesopore volume than sample $\mathrm{C}$ obtained by physical activation. It is noted that the surface area and pore volume of sample $\mathrm{C}$ decreased after acid oxidation. This result should arise from the inaccessibility of $\mathrm{N}_{2}$ molecule, which was used as a probe molecule for isotherm measurement, into the internal adsorption sites caused by the presence of functional groups at the pore entrance of slit-shaped graphitic planes and possibly by the collapse of some thin pore walls due to the strong effect of oxidizing agents [19, 20]. This lowering in the accessible amount of $\mathrm{N}_{2}$ for the oxidized carbons is further evident from the decrease in the maximum amount of nitrogen adsorbed with increasing degree of surface oxidation (data not shown here). The heat treated samples (sample C4-700 and C4-900) showed much higher surface area and micropore volume than those of the parent oxidized carbon. This is to be expected since the thermal treatment of an oxidized carbon at high temperatures in an inert atmosphere would cause the detachment of surface functional groups, thus giving rise to the restoration of its accessible porous properties. 
Table 1. Textural characteristics and $\mathrm{pH}$ at point of zero charge $\left(\mathrm{pH}_{\mathrm{PZC}}\right)$ of the test activated carbons.

\begin{tabular}{|c|c|c|c|c|c|c|}
\hline \multirow{2}{*}{ Sample } & $\mathrm{S}_{\mathrm{BET}}$ & $\mathbf{V}_{\text {mic }}$ & $\mathbf{V}_{\text {meso }}$ & $\mathbf{V}_{\mathrm{T}}$ & $\overline{\mathbf{D}}$ & \multirow{2}{*}{$\mathrm{pH}_{\mathrm{PZC}}$} \\
\hline & $\left(\mathrm{m}^{2} / \mathrm{g}\right)$ & $\left(\mathrm{cm}^{3} / \mathrm{g}\right)$ & $\left(\mathrm{cm}^{3} / \mathrm{g}\right)$ & $\left(\mathrm{cm}^{3} / \mathrm{g}\right)$ & $(\mathrm{nm})$ & \\
\hline $\mathrm{C}$ & 977 & $0.44(88 \%)$ & $0.06(12 \%)$ & 0.50 & 2.03 & 8.57 \\
\hline C1 & 905 & $0.40(85 \%)$ & $0.07(15 \%)$ & 0.47 & 2.09 & 6.99 \\
\hline $\mathrm{C} 2$ & 852 & $0.37(84 \%)$ & $0.07(16 \%)$ & 0.44 & 2.08 & 6.87 \\
\hline C4 & 581 & $0.25(83 \%)$ & $0.05(17 \%)$ & 0.30 & 2.08 & 5.48 \\
\hline C8 & * & * & * & * & * & ** \\
\hline C16 & $*$ & * & $*$ & $*$ & $*$ & $* *$ \\
\hline C24 & * & * & * & * & * & ** \\
\hline C48 & * & $*$ & * & $*$ & $*$ & ** \\
\hline C4-700 & 1140 & $0.51(86 \%)$ & $0.08(14 \%)$ & 0.59 & 2.05 & 8.65 \\
\hline C4-900 & 1144 & $0.51(88 \%)$ & $0.07(12 \%)$ & 0.58 & 2.03 & 8.98 \\
\hline $\mathrm{CZ}$ & 1079 & $0.47(80 \%)$ & $0.12(20 \%)$ & 0.59 & 2.18 & 7.80 \\
\hline $\mathrm{CZ4}$ & 525 & $0.26(79 \%)$ & $0.07(21 \%)$ & 0.33 & 2.09 & 6.95 \\
\hline W & 738 & $0.27(69 \%)$ & $0.12(31 \%)$ & 0.39 & 2.12 & $* *$ \\
\hline
\end{tabular}

The amounts and distribution of oxygen acidic groups and basic groups on activated carbon surface, as determined from Boehm titration, are shown in Fig. 2(a). It is seen that the total acidic group increased after oxidation. About fourfold increase in the acidic content with increasing oxidation time from 1 to 4 hours was observed, but from 4 to 48 hours the increase was only $13.5 \%$. Therefore, the oxidation time of 4 hours was considered to be adequate to obtain a fully oxidized carbon for further dye adsorption study. The $\mathrm{HNO}_{3}$ oxidation of all samples gave the acidic functional group content in the following order: carboxylic acid $>$ phenolic $>$ lactonic. This maximum creation of carboxylic acid content by oxidizing activated carbon surface with $\mathrm{HNO}_{3}$ was also reported in the previous work [21]. When comparing with the original carbon, the basic contents decreased after the $\mathrm{HNO}_{3}$ treatment and there was a tendency to decrease with increasing oxidation time. The observed decrease in basic content has been attributed to the conversion of some basic groups such as ketone to carboxylic acid and lactone [22] and this may in part explain the largest percentage increase of carboxylic acid in these oxidized carbons.

In order to further study the effect of surface chemistry on dye adsorption, the oxidized sample was heat-treated in an inert atmosphere of $\mathrm{N}_{2}$ to selectively remove some of the surface oxygen functional groups. Heat treatment process reduced the amount of acidic functional groups as indicated in Fig. 2(b) (cf. C4 versus C4-700 and C4-900). In addition, carboxylic acid is most sensitive to heat treatment, i.e., its content decreased in the largest percentage ( 83 and $89 \%$ for heating temperatures of 700 and $900^{\circ} \mathrm{C}$, respectively), as compared to the other two acidic groups. Furthermore, the thermal treatment developed more of the basic groups on the carbon surface. This result could arise from the transformation of some acidic groups into Bronsted basic groups at the high treatment temperature or from the increase in Lewis basic content. The latter effect probably comes from the fact that heat treatment removed some of the electron withdrawing groups (carboxylic acid and lactonic groups), thus leading to the increase in Lewis basic sites which are associated with $\pi$ electron density within the carbon basal plane [23]. 


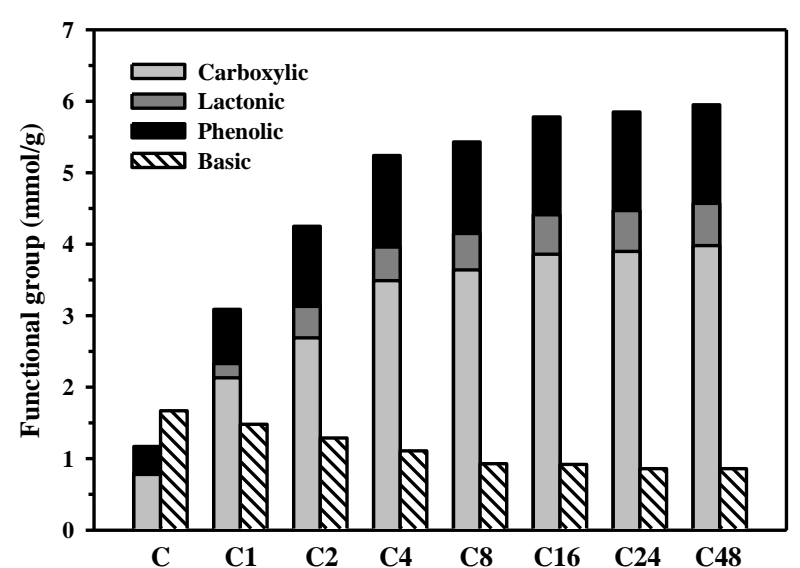

(a)

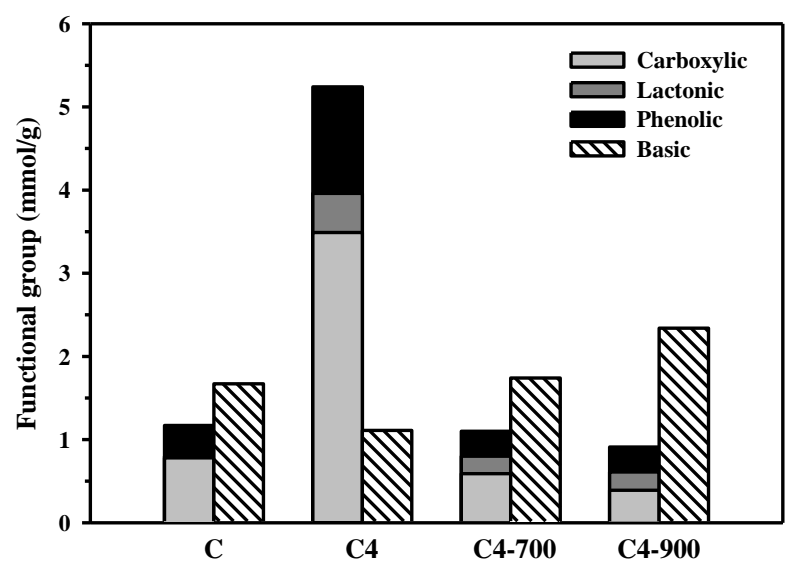

(b)

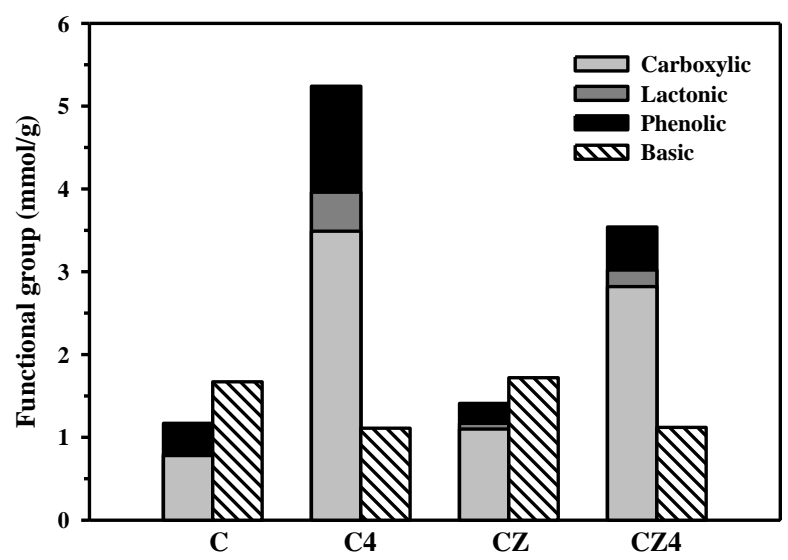

(c)

Fig. 2. Concentration of surface functional groups on coconut-shell activated carbon surface.

The contents and types of surface oxygen functional groups of the chemically activated carbon are displayed in Fig. 2(c). The chemically activated carbon (sample CZ) prepared from coconut shell contained slightly higher surface group contents but gave relatively the same percentage distribution of functional groups as compared to the physically activated carbon (sample C). However, when sample CZ was oxidized (sample CZ4), a much lower content of oxygen functional groups was noticed compared to sample C4, but the order of acidic group content of both samples remained the same. It is probable that the physically activated carbon could contain greater surface defects due to its higher activation temperature, thus allowing the physically activated carbon to be more susceptible to oxidation treatment and hence producing a larger number of surface oxygen functional groups.

Table 1 also lists the values of point of zero charge ( $\mathrm{pH}$ PZC) of various types of activated carbons. As seen, the oxidized carbons exhibit lower $\mathrm{pH}_{\mathrm{PZC}}$ values than that of the original activated carbon. This indicates that all original carbons which have a basic surface become acidic after oxidation. The order of the $\mathrm{pH}_{\mathrm{PZC}}$ values is in agreement with the amount of acidic functional groups obtained from Boehm titration, that is, the higher the content of acidic functional groups, the lower is the $\mathrm{pH}_{\mathrm{PzC}}$. The oxidized acidic carbon surfaces become basic again after their heat treatments at high temperatures.

\subsection{Adsorption Studies}

\subsubsection{Adsorption kinetics}

The kinetics of dye complex adsorption by the original and oxidized carbons (sample C, CZ, C4) was studied and the results are shown plotted in Fig. 3. The difference in the amount of dye adsorbed among these samples can be noticed but their adsorption kinetics followed a common trend. That is, the amount 
adsorbed increased with time and finally attained equilibrium within about $4320 \mathrm{~min}$. (72 hours). The time of $4320 \mathrm{~min}$. was thus selected to be the suitable adsorption time to achieve the final equilibrium condition for dye adsorption. The long equilibrium time could be attributed to the slow diffusion rate of the relatively large size of the dye adsorbate inside the adsorbent pores and coupled possibly by the hindrance effect among the adsorbed molecules. As a result of this mass transfer resistance, the use of smaller size adsorbent particles should to a certain extent increase the diffusion rate by decreasing the diffusion path of adsorbate from the exterior surface to the internal adsorption site.

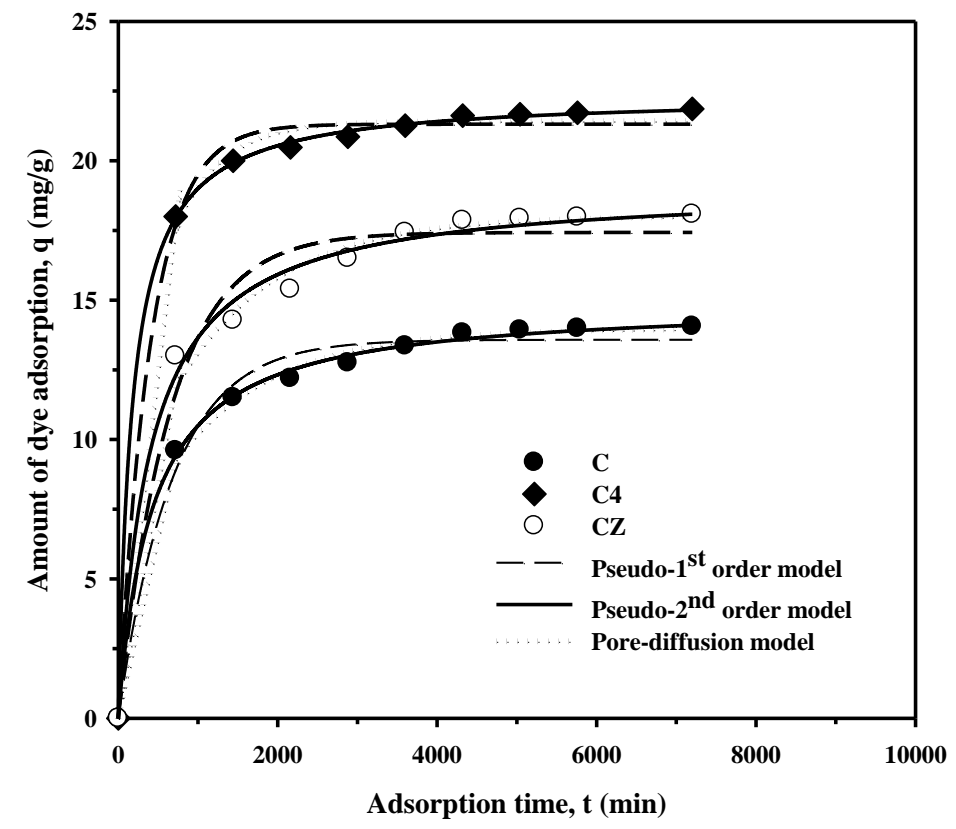

Fig. 3. Kinetics of dye adsorption and comparison with various kinetic models.

The kinetics of dye adsorption in this study was analyzed using the two commonly used rate equations, namely the pseudo-first order model and the pseudo-second order model [24, 25], shown as Eq. (2) and Eq. (3), respectively.

$$
\frac{d q_{t}}{d t}=k_{1}\left(q_{e}-q_{t}\right)
$$

and

$$
\frac{d q_{t}}{d t}=k_{2}\left(q_{e}-q_{t}\right)^{2}
$$

Integrating the above equations gives in non-linear forms:

$$
q_{t}=q_{e}\left[1-e^{-k_{1} t}\right]
$$

and

$$
q_{t}=\frac{q_{e}^{2} k_{2} t}{1+q_{e} k_{2} t}
$$


where $\mathrm{q}_{\mathrm{e}}$ is the amount of dye adsorbed at equilibrium ( $\mathrm{mg} / \mathrm{g}$ carbon), $\mathrm{q}_{\mathrm{t}}$ is the amount adsorbed at time $\mathrm{t}$, $\mathrm{k}_{1}\left(\mathrm{~min}^{-1}\right)$ and $\mathrm{k}_{2}(\mathrm{~g} / \mathrm{mg}$-min) are the corresponding rate constants.

The prediction of adsorption kinetics can also be achieved employing a pore-diffusion model [26], from which the adsorption process is governed by intra-particle diffusion of adsorbate molecules. The final solution for the fractional uptake of adsorbate $(\mathrm{F})$, assuming a spherical adsorbent and a linear adsorption isotherm reads

$$
F=\frac{q_{t}}{q_{e}}=1-\left(\frac{6}{\pi^{2}}\right) \sum_{n=1}^{\infty} \frac{1}{n^{2}} e^{-n^{2} \pi^{2} \tau}
$$

where $\tau$ is a non-dimensional time parameter defined as, $\tau=D_{e} t / R_{p}^{2}, D_{e}$ is the effective pore diffusivity and $R_{p}$ is the radius of adsorbent particle. At long adsorption time (close to equilibrium), only the first term of the series in Eq. (6) can be considered. Thus,

$$
F=1-\left(\frac{6}{\pi^{2}}\right) e^{\frac{-\pi^{2} D_{e} t}{R_{p}{ }^{2}}}
$$

The three kinetic model equations, Eq. (4), (5) and (7), were used to fit the experimental kinetic data of dye adsorption. Table 2 lists the values of kinetic parameters derived by applying a regression analysis along with the correlation coefficients $\left(\mathrm{R}^{2}\right)$ and the comparison between experimental data and those predicted by each model is shown in Fig. 3. Based on the values of correlation coefficient, the kinetic data of dye adsorption were perfectly fitted with the pseudo-second order model $\left(\mathrm{R}^{2}>0.99\right)$ and the order of predictive capability of the models is: pseudo- $2^{\text {nd }}$ order $>$ pore diffusion $>$ pseudo- $1^{\text {st }}$ order model. The equilibrium adsorbed capacities $\left(\mathrm{q}_{\mathrm{e}}\right)$ estimated from the three models agreed reasonably well with the order of $\mathrm{q}_{\mathrm{e}}$ for the activated carbons studied, that is, $\mathrm{C} 4>\mathrm{CZ}>\mathrm{C}$. The difference in the maximum adsorbed capacity is ascribed to the difference in the adsorption mechanisms as discussed in section 3.2.2. Reasonably good description of adsorption kinetics by the pore-diffusion model (see Fig. 3) indicates that diffusion of dye molecules through the internal pores of activated carbon is probably the rate-determining step of the overall adsorption process. In other words, the rate of diffusion of adsorbate molecules through the external fluid film and the rate of adsorption on the active sites are much faster than the intra-particle diffusion rate.

It is observed that the effective pore diffusivities $\left(\mathrm{D}_{\mathrm{e}}\right)$ of non-oxidized sample $\mathrm{C}$ and $\mathrm{CZ}$ are comparable but are about half less than that of the oxidized sample $\mathrm{C} 4$. The higher $\mathrm{D}_{\mathrm{e}}$ value of sample $\mathrm{C} 4$ is attributed to the higher affinity of this carbon towards the dye molecules due to the presence of a large number of acid surface functional groups. This would lead to a faster rate of adsorption and thus giving less concentration gradient of adsorbate along the diffusion path inside the adsorbent pores. The values of effective pore diffusivity of the cationic dye reported in this work was found to vary in the range from $1.82 \times 10^{-9}$ to $3.76 \times 10^{-9} \mathrm{~cm}^{2} / \mathrm{s}$ which can be compared to the values of $3.12 \times 10^{-7}$ to $5.91 \times 10^{-7} \mathrm{~cm}^{2} / \mathrm{s}$ for the adsorption of a cationic dye (astrazon yellow 7GL) by apricot stone activated carbon [27]. The difference of the pore diffusivity by about two order of magnitude should be due principally to the differences in the pore structure of the tested activated carbons (surface area and pore size distribution) and the properties of the adsorbed dyes (e.g. molecular size and shape).

Table 2. Kinetic parameters of various adsorption kinetic models for dye adsorption with coconut shell

\begin{tabular}{|c|c|c|c|c|c|c|c|c|c|}
\hline \multirow[b]{2}{*}{ Sample } & \multicolumn{3}{|c|}{ Pseudo-first order } & \multicolumn{3}{|c|}{ Pseudo-second order } & \multicolumn{3}{|c|}{ Pore diffusion } \\
\hline & $\begin{array}{c}\mathrm{q}_{\mathrm{e}} \\
(\mathrm{mg} / \mathrm{g})\end{array}$ & $\begin{array}{c}\mathrm{k}_{1} \\
\left(\mathrm{~min}^{-1}\right)\end{array}$ & $\mathbf{R}^{2}$ & $\begin{array}{c}\mathrm{q}_{\mathrm{e}} \\
(\mathrm{mg} / \mathrm{g})\end{array}$ & $\begin{array}{c}\mathrm{k}_{2} \\
(\mathrm{~g} / \mathrm{mg}- \\
\mathrm{min})\end{array}$ & $\mathbf{R}^{2}$ & $\begin{array}{c}\mathrm{q}_{\mathrm{e}} \\
(\mathrm{mg} / \mathrm{g})\end{array}$ & $\begin{array}{c}D_{\mathrm{e}} \\
\left(\mathrm{cm}^{2} / \mathrm{s}\right)\end{array}$ & $\mathbf{R}^{2}$ \\
\hline $\mathrm{C}$ & 13.58 & $1.48 \times 10^{-3}$ & 0.8644 & 15.10 & $1.41 \times 10^{-4}$ & 0.9997 & 13.91 & $1.82 \times 10^{-9}$ & 0.9731 \\
\hline C4 & 21.31 & $2.46 \times 10^{-3}$ & 0.8366 & 21.65 & $5.45 \times 10^{-3}$ & 0.9973 & 21.39 & $3.76 \times 10^{-9}$ & 0.8980 \\
\hline $\mathrm{CZ}$ & 17.43 & $1.53 \times 10^{-3}$ & 0.7477 & 18.12 & $5.64 \times 10^{-4}$ & 0.9923 & 17.91 & $1.83 \times 10^{-9}$ & 0.9314 \\
\hline
\end{tabular}
activated carbons. 


\subsubsection{Adsorption isotherms}

Figure 4(a) shows the effect of adsorbent dosage on the percent adsorption of the dye complex for a typical adsorbent (sample C4), with initial dye concentration and solution volume of $220 \mathrm{~g} / \mathrm{L}$ and $25 \mathrm{~mL}$, respectively. Obviously, increasing the adsorbent dosage at a fixed dye concentration provides more available adsorption sites and thus giving increased percent adsorption. As the adsorbent dosage increased from 0.05 to 0.2 gram, the percent adsorption increased rapidly from 45 to $98 \%$ and remained substantially constant at higher dosage. In obtaining experimental isotherm data, the amount of activated carbon used was therefore varied in the range from 0.05-0.2 gram using a fixed dye solution volume of $25 \mathrm{~mL}$.

It is generally known that $\mathrm{pH}$ of solution can influence the adsorption of ionic dyes on an adsorbent. The amount of adsorption is primarily controlled by surface charge on the carbon, which in turn depends on the solution $\mathrm{pH}[28,29]$. The fully oxidized carbon (sample C4) when immersed in the solution is expected to develop more of negative surface charge from the dissociation of its high content of surface oxygen functional groups such as carboxylic acid. The effect of solution $\mathrm{pH}$ on the adsorption of dye solution by this oxidized carbon is illustrated in Fig. 4(b). The amount of dye adsorbed first increased sharply with increasing $\mathrm{pH}$ from 2.0 to 3.0 , followed by a slow increase before attaining a plateau for $\mathrm{pH}$ values in the range from 4.0-4.5, corresponding to more than $95 \%$ removal of the dye.

It was found experimentally that the dye uptake was not possible at $\mathrm{pH}$ greater than about 5 , since the precipitation of $\mathrm{Al}(\mathrm{OH})_{3}$ started to occur in the system. The low adsorption of cationic dye molecules at the low solution $\mathrm{pH}$ results from the lower number of negatively charged active sites of proton-donating functional groups on the carbon surface at this low $\mathrm{pH}$, and this gives less electrostatic-force interaction. Similar reasoning can be applied to explain the increased amount of dye adsorbed as the $\mathrm{pH}$ is increased, that is the increase is due to increasing in electrostatic attraction between the more negatively charged surface of the carbon and the cationic dye molecules. From these results, the $\mathrm{pH}$ of 4 was considered to be suitable for maximum adsorption of the cationic dye in this study. Since the $\mathrm{pH}$ range of dye solution after silk dyeing was found to lie between 3.8- 4.0, the spent dye solution was therefore used as a feed solution throughout the adsorption experiments in this work without adjusting the $\mathrm{pH}$ value.

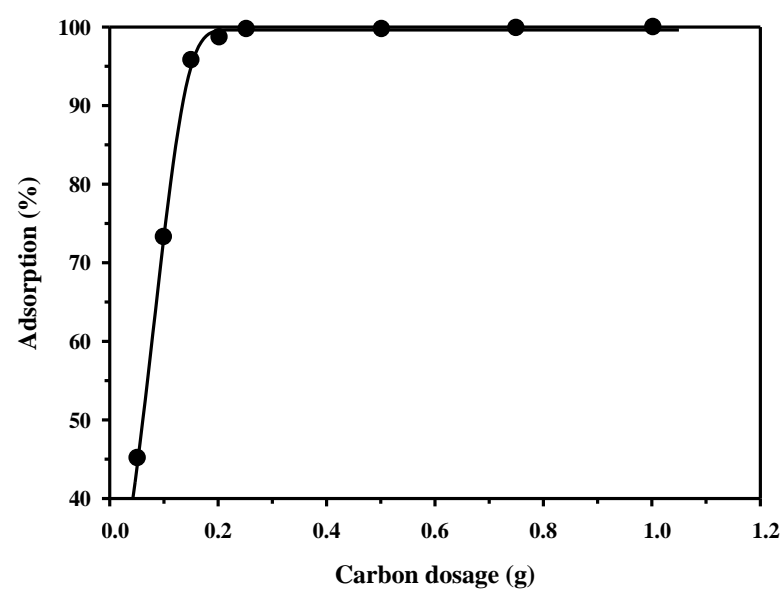

(a)

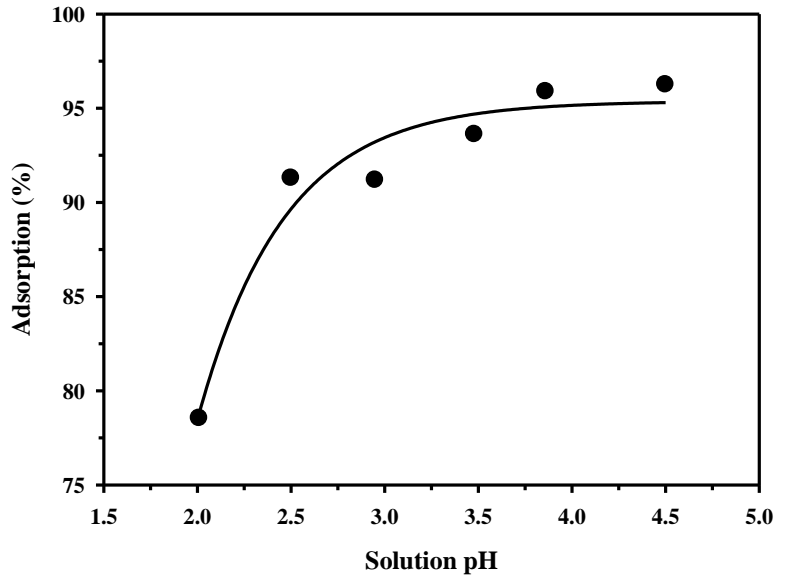

(b)

Fig. 4. Effect of carbon dosage (a) and solution $\mathrm{pH}$ (b) on dye adsorption efficiency of sample C4 activated carbon at $30^{\circ} \mathrm{C}$ (solution volume $=25 \mathrm{~mL}$, initial dye concentration $=220 \mathrm{mg} / \mathrm{L}$ ).

Three well-known isotherm equations were tested against the experimental isotherm data in this study, including Langmuir, Freundlich and Sips equations, as shown in Eqs. (8)-(10), respectively.

Langmuir:

$$
q_{e}=\frac{q_{m L} K_{L} C_{e}}{1+K_{L} C_{e}}
$$

Freundlich:

$$
q_{e}=K_{F} C_{e}^{1 / n_{F}}
$$


Sips:

$$
q_{e}=\frac{q_{m S}\left(K_{S} C_{e}\right)^{1 / n_{S}}}{1+\left(K_{S} C_{e}\right)^{1 / n_{S}}}
$$

Langmuir equation for monolayer adsorption on a homogeneous surface where the adsorption energy is constant contains two model parameters, namely the maximum monolayer capacity $\left(\mathrm{q}_{\mathrm{mL}}\right)$ and the Langmuir constant $\left(\mathrm{K}_{\mathrm{L}}\right)$ which is a measure of how strong an adsorbate molecule is attracted onto an adsorbent surface. The two-parameter Freundlich equation was developed based on monolayer adsotption on a heterogeneous patchwise surface, that is there is a distribution of adsorption energy which is characterized by a parameter $\mathrm{n}_{\mathrm{F}}$. The larger the value of $\mathrm{n}_{\mathrm{F}}$, the higher the heterogeneity of the surface and the more non-linearity of the isotherm. Sips equation is a three-parameter empirical model ( $\left.\mathrm{q}_{\mathrm{ms}}, \mathrm{K}_{\mathrm{s}}, \mathrm{n}_{\mathrm{s}}\right)$ that has the characteristic of Freundlich isotherm but possesses a finite saturation limit at high concentration similar to Langmuir equation.

Table 3 lists the fitted adsorption model parameters by regression analysis for all coconut shell activated carbons studied. By considering the values of correlation coefficients $\left(\mathrm{R}^{2}\right)$, the following order of prediction capability of the adsorption models is observed: Sips $>$ Langmuir $>$ Freundlich. However, since Langmuir equation can give the correct trend of isotherm data (see Fig. 5) and its model accuracy is comparable to that of Sips equation plus the fact that Langmuir equation is more flexible (a two-parameter equation), it was decided to use Langmuir equation in describing the adsorption isotherms of Al-dye complex in this work. From Table 3 and Fig. 2(a), there is a clear indication that the Langmuir constant $\left(\mathrm{K}_{\mathrm{L}}\right)$ increased with increasing degree of surface oxidation, in the following sequence: $\mathrm{C} 4-900<\mathrm{C} 4700<\mathrm{C} 1<\mathrm{C} 2<\mathrm{C} 4$. This result emphasizes the important role of oxygen functional groups on the affinity of dye molecules towards the activated carbon surfaces. Similar to the Langmuir constant, the Freundlich isotherm constant, $\mathrm{n}_{\mathrm{F}}$, which reflects the degree of surface heterogeneity, was also found to increase with increasing amounts of surface oxygen groups on the carbon samples, that is $\mathrm{C} 4>\mathrm{C} 2>\mathrm{C} 1$.

Table 3. Parameters of adsorption isotherm equations for dye adsorption at $30^{\circ} \mathrm{C}$ by coconut shell activated carbons.

\begin{tabular}{|c|c|c|c|c|c|c|c|c|c|c|}
\hline \multirow{3}{*}{ Sample } & \multicolumn{3}{|c|}{ Langmuir } & \multicolumn{3}{|c|}{ Freundlich } & \multicolumn{4}{|c|}{ Sips } \\
\hline & $\mathrm{q}_{\mathrm{mL}}$ & $\mathbf{K}_{\mathrm{L}}$ & $\mathbf{R}^{2}$ & $\mathbf{K}_{\mathrm{F}}$ & $\mathrm{n}_{\mathrm{F}}$ & $\mathbf{R}^{2}$ & $\mathrm{q}_{\mathrm{mS}}$ & $\mathbf{K}_{\mathbf{S}}$ & $\mathrm{n}_{\mathrm{s}}$ & $\mathbf{R}^{2}$ \\
\hline & (mg/g) & $(\mathrm{L} / \mathrm{mg})$ & & & & & $(\mathrm{mg} / \mathrm{g})$ & $(\mathrm{L} / \mathrm{mg})$ & & \\
\hline $\mathrm{C}$ & 16.96 & 0.382 & 0.9796 & 7.27 & 5.24 & 0.9044 & 16.90 & 0.384 & 0.976 & 0.9796 \\
\hline $\mathrm{C} 1$ & 39.41 & 0.143 & 0.9632 & 9.63 & 3.34 & 0.8528 & 36.83 & 0.170 & 0.730 & 0.9743 \\
\hline C2 & 40.74 & 0.250 & 0.9710 & 12.74 & 3.87 & 0.8552 & 37.88 & 0.309 & 0.591 & 0.9901 \\
\hline C4 & 42.66 & 0.757 & 0.9755 & 18.36 & 5.01 & 0.9097 & 44.62 & 0.622 & 1.273 & 0.9802 \\
\hline C4-700 & 39.92 & 0.048 & 0.9723 & 5.43 & 2.49 & 0.9279 & 33.22 & 0.072 & 0.608 & 0.9856 \\
\hline C4-900 & 42.24 & 0.028 & 0.9639 & 4.08 & 2.25 & 0.9369 & 35.97 & 0.038 & 0.728 & 0.9673 \\
\hline CZ & 50.23 & 0.023 & 0.9757 & 3.74 & 2.03 & 0.9665 & 53.53 & 0.020 & 1.072 & 0.9759 \\
\hline CZ4 & 46.26 & 0.044 & 0.9501 & 6.13 & 2.54 & 0.8864 & 37.96 & 0.064 & 0.533 & 0.9763 \\
\hline
\end{tabular}




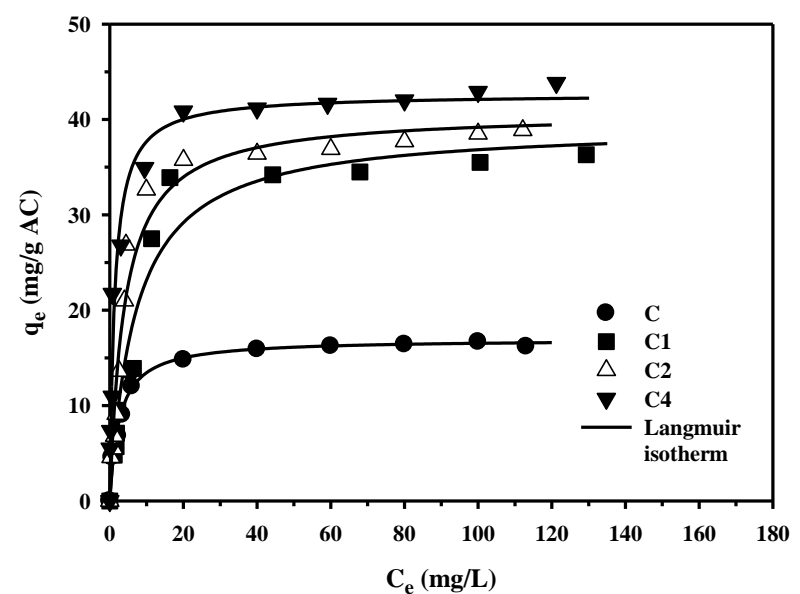

(a)

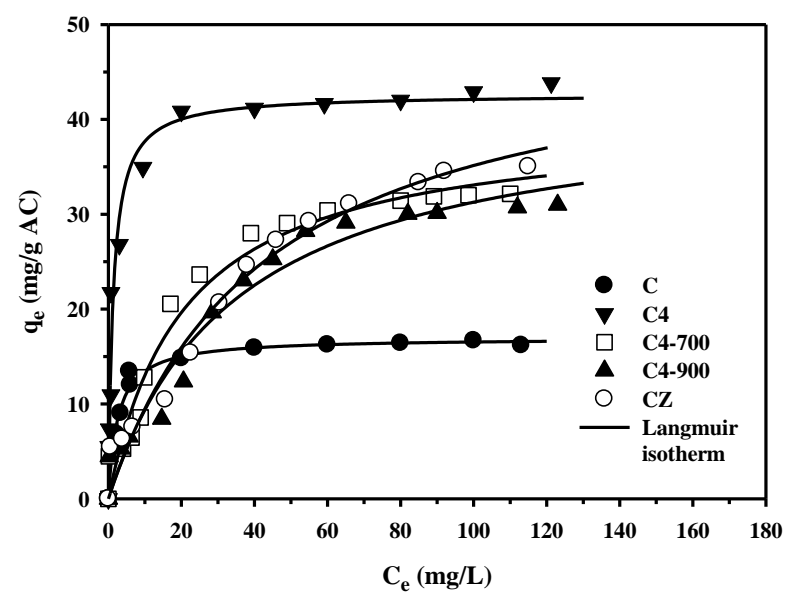

(b)

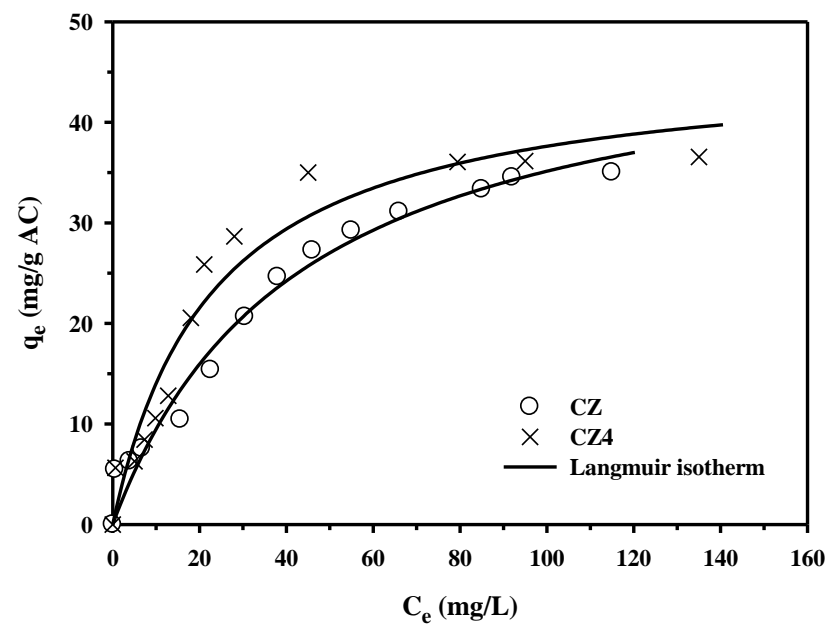

(c)

Fig. 5. Adsorption isotherms of dye complex at $30^{\circ} \mathrm{C}$ for coconut shell activated carbons.

Figure 5(a) compares adsorption isotherms of dye complex on C, C1, C2 and C4 carbon samples. The adsorption capacity was increased in the following order: $\mathrm{C}<\mathrm{C} 1<\mathrm{C} 2<\mathrm{C} 4$. Although the non-oxidized carbon (sample C) has the highest surface area, it contains mainly micropores which do not permit the transport and adsorption of relatively large dye molecules inside the pores. This result emphasizes the fact that a proper porous structure of carbon adsorbent is of prime importance for the adsorption of dye in this study. It is clear that the dye adsorption capacity was greatly enhanced when the original carbon was oxidized with $\mathrm{HNO}_{3}$ that increased the number of oxygen surface functional groups. The increasing adsorption capacity follows the same order of increasing acid group contents, i.e., $\mathrm{C} 1<\mathrm{C} 2<\mathrm{C} 4$. The higher amount of acid functional groups which provides more negative sites is the main reason for higher adsorption capacity due to the enhancement of adsorption by electrostatic interaction. Therefore, the amounts of surface functional groups play a major role in the adsorption of this cationic dye by these carbons.

After carbon C4 was subjected to decomposition of surface oxygen functional groups by heat treatment at two elevated temperatures, the adsorbed amounts of dye by the two carbon samples (sample C4-700 and C4-900) were reduced drastically, as shown in Fig. 5(b). The results from Boehm titration indicated that the heat treated carbons contained less acidic functional groups on the carbon surface. Since carboxylic acid group is most sensitive to heat treatment [30], its amount is reduced thermally much more than the other functional groups ( $\sim 83 \%$ reduction). Therefore, the lower amount of dye uptake of heat treated carbons is due primarily to the decreasing amount of carboxylic acid. When compared to the nonoxidized sample $\mathrm{C}$, these heat treated carbons still gave higher dye adsorption, although they contained comparatively lower amount of surface functional groups. It is possible that proportionally higher surface 
area and pore volume of these two carbons after heat treatment (see Table 1) could be responsible for higher dye uptake. This signifies that dispersive force interaction will come into play for carbons with reasonably high proportion of large pores, even though the number of surface functional groups is relatively low.

The role of pore texture on the adsorbed capacity of dye can be further examined from Fig. 5(b) by comparing isotherms of the physically activated carbon (sample $\mathrm{C}$ ) and the chemically activated carbon (sample CZ) which contains larger surface area and mesopore volume (see Table 1). It is obvious that sample CZ had higher adsorbed capacity than sample C and gave the isotherm lying among those of heat treated samples, emphasizing the adsorption of dye molecules by dispersive interaction between the delocalized $\pi$-electrons of the graphene layer and the free electrons of the dye molecules. As Fig. 5(c) shows, when sample $\mathrm{CZ}$ was further oxidized under the same condition as sample $\mathrm{C} 4$, the oxidized carbon (sample CZ4) gave increased dye uptake similarly to sample C4 when the original carbon (sample C) was oxidized. However, it was found for oxidized samples CZ4 and C4 that the percentage increasing of the adsorbed amount of the former relative to the percentage increasing of its oxygen functional groups is much less than that of the latter. From this finding, it may be concluded that the adsorption of the cationic dye complex in this study depends on the relative effect of both pore structure and the existence of surface functional groups. To achieve good adsorption capacity, a rather small pore-size carbon requires the fixation of oxygen functional groups to take advantage of electrostatic attraction, whereas for a carbon with relatively large pore size the effect of dispersive-force interaction is the dominant mechanism for the dye adsorption and the role of surface functional groups is of secondary importance.

The treatment of spent dye solution in this study by activated carbons removed not only the molecules of dye complex but also aluminium ion $\left(\mathrm{Al}^{3+}\right)$ left from mordanting the natural dye with excess alum. Activated carbon prepared from eucalyptus wood by physical activation with carbon dioxide was employed to study the adsorption of the cationic dye complex and aluminium ion from the spent dye solution. The concentrations of aluminium in both forms (as [Al(brazilein) ${ }_{2}{ }^{+}$complex and as $\mathrm{Al}^{3+}$ ) presenting in the bulk solution phase and in the adsorbed phase at equilibrium were determined from the knowledge of the initial total aluminium content, the final total aluminium concentration and the mole ratio of 1:2 for $\mathrm{Al}$ and brazilein in the dye complex.

Figure 6(a) shows adsorption isotherm of the dye complex which can be fitted reasonably well with the Langmuir equation, giving $\mathrm{q}_{\mathrm{mL}}$ and $\mathrm{K}_{\mathrm{L}}$ to be $1403 \mathrm{mg} / \mathrm{g}$ and $0.026 \mathrm{~L} / \mathrm{mg}$, respectively. It is interesting to note that the maximum monolayer capacity $\left(\mathrm{q}_{\mathrm{mL}}\right)$ of this carbon adsorbent is much larger than those of all coconut shell carbons (see Table 3 for comparison), although their porous properties are not so greatly different (see Table 1). Figure 6(b) illustrates the equilibrium isotherm for the adsorption of aluminium associated with the brazilein dye. As expected, the shape of isotherm is similar to that of the dye complex and is well described by the following Langmuir equation,

$$
q_{e, A l-d y e}=\frac{q_{m L} K_{L} C_{e, A l-d y e}}{1+K_{L} C_{e, A l-d y e}}
$$

with $\mathrm{q}_{\mathrm{mL}}=31.34 \mathrm{mg} / \mathrm{g}, \mathrm{K}_{\mathrm{L}}=0.87 \mathrm{~L} / \mathrm{mg}$ and $\mathrm{R}^{2}=0.9565$. The adsorption isotherm of aluminium ion $\left(\mathrm{Al}^{3+}\right)$ in dye solution is presented in Fig. 6(c). It exhibits a linear type of isotherm, indicative of adsorption in the low concentration region, and the isotherm equation is represented by

$$
q_{e, \mathrm{Al}^{3+}}=K_{H} C_{e, \mathrm{Al}} \mathrm{l}^{3+}
$$

where $K_{H}$ is the Henry's constant and has the value of $0.74 \mathrm{~L} / \mathrm{mg}$.

Since aluminium in the spent dye solution exists mainly as $\mathrm{Al}^{3+}(\sim 70 \%$ out of $11.48 \mathrm{mg} / \mathrm{L}$ of total aluminium content), the effective removal of aluminium ion by adsorption is of particular concern. Apart from the acquired isotherm data for aluminium adsorption which is essential for the general design of an adsorption system, a simple correlation between adsorption efficiency and adsorbent dosage should be useful for the preliminary assessment of a selected adsorbent. Figure 6(d) shows the effect of adsorbent dosage on the percent removal of total aluminium and aluminium ion from dye solution and the following empirical equations were proposed: 
For total aluminum:

$$
\eta_{t}=\frac{138 W_{C}}{1+1.36 W_{C}}, R^{2}=0.8955
$$

For aluminium ion:

$$
\eta_{i}=\frac{57 W_{C}}{1+0.55 W_{C}}, R^{2}=0.9784
$$

where $\eta_{t}$ and $\eta_{i}$ are the percent removal efficiencies of total aluminium and aluminium ion, respectively, and $W_{c}$ is the carbon dosage in $\mathrm{g} / \mathrm{L}$ of dye solution. As an example of calculation, if the maximum allowable aluminium content in the discharge effluent is equal to the environmental standard of $0.2 \mathrm{mg} / \mathrm{L}$ for drinking water [4], the removal efficiency of $98.26 \%(=100(11.48-0.2) / 11.48)$ is required and the amount of eucalyptus activated carbon needed $\left(\mathrm{W}_{\mathrm{C}}\right)$ is calculated from Eq. (13) to be $22.5 \mathrm{~g}$ carbon/L solution.

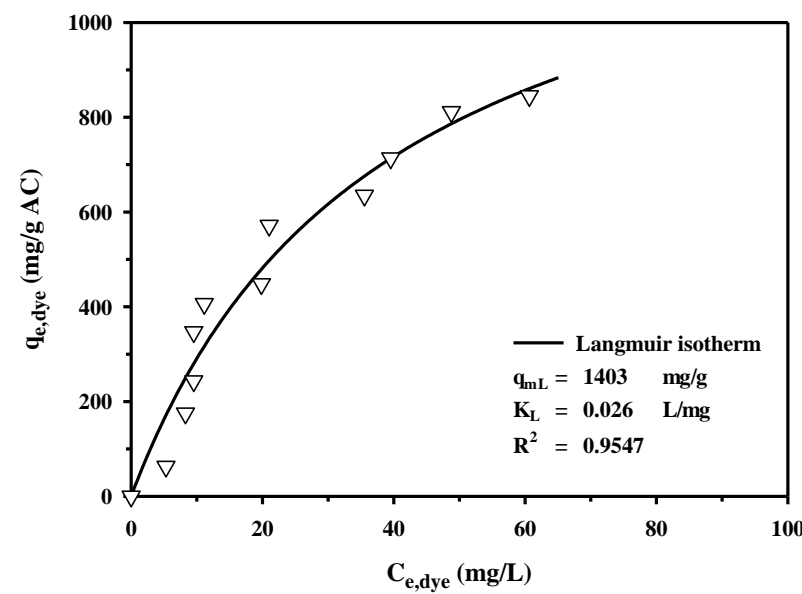

(a)

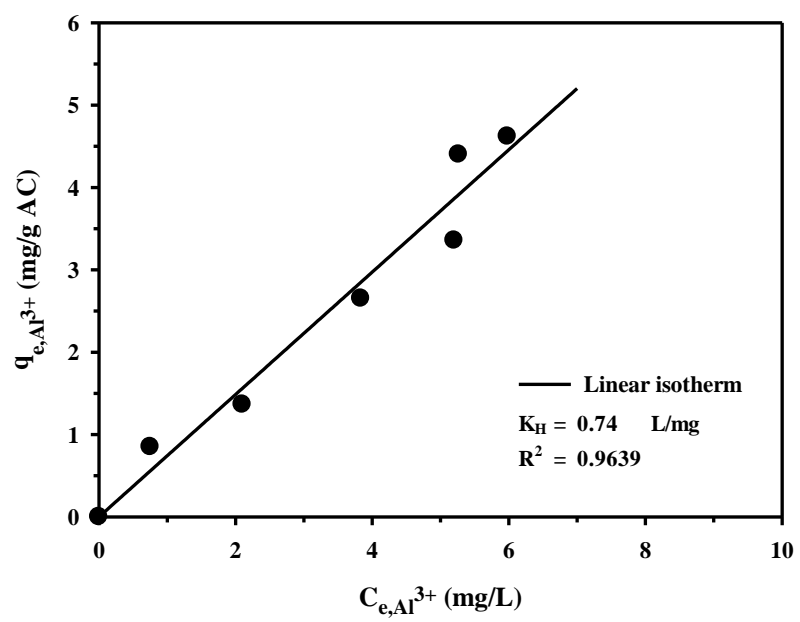

(c)

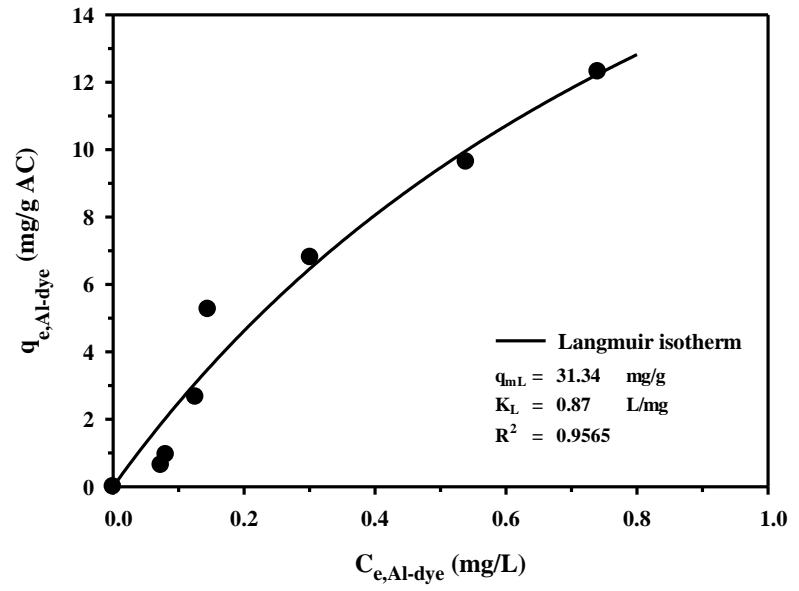

(b)

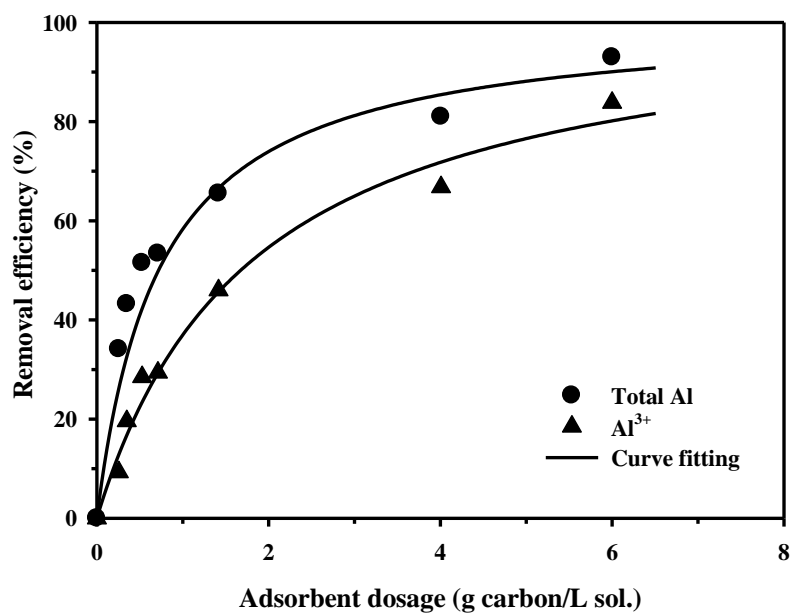

(d)

Fig. 6. Adsorption isotherms of (a) residual Al-dye complex, (b) aluminium in dye complex, (c) aluminium ion and (d) effect of carbon dosage on percent adsorption of aluminium for eucalyptus activated carbon.

\section{Conclusions}

The adsorption of natural cationic dye, remaining in the effluent in the form of [Al(brazilein) $\left.{ }_{2}\right]^{+}$complex after silk dyeing, was investigated using coconut shell activated carbons having different porous structure and surface chemistry. Moreover, the removal of residual aluminium ion existing in the dye solution by adsorption with eucalyptus based activated carbon was also undertaken. It was found that the time to reach 
adsorption equilibrium of this dye complex was relatively long, about 72 hours, indicating that the adsorption process was probably controlled by intra-particle diffusion of dye molecules. The kinetics of dye adsorption was best described by the global pseudo-second order model, followed by the pore diffusion model and the pseudo-first order model, respectively. Adsorption isotherms of all activated carbons tested were reasonably well fitted by the two-parameter Langmuir equation. Coconut shell activated carbon containing a large proportion of micropores $(>80 \%)$ was not effective in adsorbing a relatively large size of dye molecules. However, almost a threefold increase in adsorption capacity was observed when the carbon adsorbent was fully oxidized to introduce acidic surface groups, from which the dye uptake was enhanced by electrostatic interaction between negatively charged surface of the carbon and the positively charged dye. On the other hand, coconut shell carbon with relatively higher mesopore volume $(>20 \%)$ could adsorb the cationic dye about three times higher than the microporous carbon, although their surface area and total pore volume were not significantly different. The mechanism of adsorption for large pore carbon is by dispersive-force attraction between the $\pi$ electrons of carbon plane and the $\pi$ electrons in the aromatic ring of the dye molecules. Adsorption of residual aluminium ion $\left(\mathrm{Al}^{3+}\right)$ from the spent dye solution was well achieved with eucalyptus based activated carbon. The adsorption of aluminium ion followed a linear type of adsorption isotherm and $80 \%$ removal efficiency could be obtained using a carbon dosage of $6 \mathrm{~g}$ carbon/ $\mathrm{L}$ of dye solution, reducing the aluminium ion content from 8.2 to $1.6 \mathrm{mg} / \mathrm{L}$.

\section{Acknowledgements}

The financial support of this work from SUT Research and Development Fund of Suranaree University of Technology is gratefully acknowledged.

\section{References}

[1] E. S. B. Ferreira, A. N. Hulme, H. McNab, and A. Quye, "The natural constituents of historical textile dyes," Chemical Society Reviews, vol. 33, pp. 329-336, 2004.

[2] X. Yan, W. Wang, D. Xing, Y. Zhao, and L. Du, "Development and optimization of a method for the analysis of brazilien by HPLC with electrochemical detection," Journal of Chromatography A, vol. 1077, pp. 329-336, 2004.

[3] K. Wongsooksin, S. Rattanaphani, M. Tangsathtikulchai, V. Rattanaphani, and J. Bremner, "Study of an $\mathrm{Al}(\mathrm{III})$ complex with the plant dye brazilein from Ceasalpinia sappan Linn.," Suranaree Journal of Science and Technology, vol. 15, pp. 159-165, 2008.

[4] A. Becaria, D.K. Lahiri, S.C. Bondy, D. Chen, A.Hamadeh, H. Li, R. Taylor, and A. Campbell, "Aluminum and copper in drinking water enhance inflammatory or oxidative events specifically in the Brain," Journal of Neuroimmunology, vol. 176, pp. 16-23, 2006.

[5] M. Kobya, E. Demirbas, E. Senturk, and M. Ince, "Adsorption of heavy metal ions from aqueous solution by activated carbon prepared from apricot stone," Bioresource Technology, vol. 96, pp.1518-1521, 2005.

[6] L. Li, P. A. Quinlivan, and R. U. Knappe, "Effects of activated carbon surface chemistry and pore structure on the adsorption of organic contaminants from aqueous solution," Carbon, vol. 40, pp. 2085-2100, 2002.

[7] E. N. El Qada, S. J. Allen, and G. M. Walker, "Adsorption of basic dyes from equilibrium solution onto activated carbons," Chemical Enginering Journal, vol. 135, pp. 174-184, 2008.

[8] A. Rodriguez, J. Garcia, G. Ovejeno, and M. Mestanza, "Adsorption of anionic and cationic dyes on activated carbon from aqueous solution: Equilibrium and kinetics," Journal of Hazardous Materials, vol. 72, pp. 1311-1329, 2009.

[9] S. Wang, Z. H. Zhu, A. Coomes, F. Haghseresht, and G. Q. Lu, "The physical and surface chemical characteristics of activated carbons and the adsorption of methylene blue from wastewater," Journal of Colloid and Interface Science, vol. 284, pp. 440-446, 2005.

[10] S. Wang, and Z. H. Zhu, "Effects of acidic treatment of activated carbons on dye adsorption," Dyes and Pigments, vol. 75, pp. 306-314, 2007.

[11] A. H. El-Sheikh, "Effect of oxidation of activated carbon on its enrichment efficiency of metal ions: Comparison with oxidized and non-oxidized multi-walled carbon nanotubes," Talanta, vol. 75, pp. 127-134, 2008. 
[12] A. N. A. El-Hendawy, "Influence of $\mathrm{HNO}_{3}$ oxidation on the structure and adsorptive properties of corncob-based activated carbon," Carbon, vol. 41, pp. 713-722, 2003.

[13] B. Xiao and K.M. Thomas, "Adsorption of aqueous metal ions on oxygen and nitrogen functionalized nanoporous activated carbons," Langmuir, vol. 21, pp. 3892-3902, 2005.

[14] L. R. Radovic, I. F. Silva, J. I. Ume, J. A. Menendez, Y. Leon, C. A. Leon, and A. W. Scaroni, “An experimental and theoretical study of the adsorption of aromatics possessing electron-withdrawing and electron-donating functional groups by chemically modified activated carbons," Carbon, vol. 35, pp. 1339-1348, 1997.

[15] M. F. R. Pereira, S. F. Soares, J. J. M. Orfao, and J. L. Figueiredo, "Adsorption of dyes on activated carbons: Influence of surface chemical groups," Carbon, vol. 41, pp. 811-821, 2003.

[16] A. A. Attia, W. E. Rashwan, and S. A. Khedr, "Capacity of activated carbon in the removal of acid dyes subsequent to its thermal treatment," Dyes and Pigments, vol. 69, pp. 128-136, 2006.

[17] Z. Hu, M. P. Srinivasan, and Y. Ni, "Novel activation process for preparing highly microporous and mesoporous activated carbons," Carbon, vol. 39, pp. 877-886, 2001.

[18] C. Tangsathitkulchai, Y. Ngernyen, and M. Tangsathitkulchai, "Surface modification and adsorption of eucalyptus wood-based activated carbon: Effects of oxidation treatment, carbon porous structure and activation method," Korean Journal of Chemical Engineering, vol. 26, pp. 1341-1352, 2009.

[19] B. Xiao, "Characterization of functionalized nanoporous carbon materials and adsorption of aqueous metal ions," Ph.D. thesis, University of Newcastle upon Tyne, United Kingdom, 2004.

[20] I. I. Salame, A. Bagreev, and T. J. Bandosz, "Revisiting the effect of surface chemistry on adsorption of water on activated carbons," Journal of Physical Chemistry B, vol. 103, pp. 3877-3884, 1999.

[21] Y. F. Jia, and K. M. Thomas, "Adsorption of cadmium ions on oxygen surface sites in activated carbon," Langmuir, vol. 16, pp. 1114-1122, 2000.

[22] M. B. Smith and J. March, March's Advanced Organic Chemistry. John Wiley \& Sons, Inc., 2007.

[23] S. Shin, J. Jang, S.H. Yoon, and I. Mochida, "A study on the effect of heat treatment on functional groups of pitch based activated carbon," Carbon, vol. 35, pp. 1739-1743, 1997.

[24] Y. S. Ho, and G. McKay, "Kinetic models for the sorption of dye from aqueous solution by wood," Process Safety and Environmental Protection, vol. 76, pp. 183-191, 1998.

[25] Y. S. Ho and G. McKay, "Pseudo-second order model for sorption processes," Process Biochemistry, vol. 34, pp. 451-465, 1999.

[26] D. D. Do, "Analysis of adsorption kinetics in a single homogeneous particle," in Adsorption Analysis: Equilibria and Kinetics. Imperial College Press, 1998, ch. 9, sec. 9.2.1, pp. 521-545.

[27] E. Demirbas, M. Kobya, and M. T. Sulak, "Adsorption kinetics of a basic dye from aqueous solutions onto apricot stone activated carbon," Bioresource Technology, vol. 99, pp. 5368-5373, 2008.

[28] M. J. Iqbal and M. N. Ashiq, "Adsorption of dyes from aqueous solutions on activated charcoal," Journal of Hazardous Materials, vol. 139, pp. 57-66, 2007.

[29] Y. S. Al-Degs, M. I. El-Barghouthi, A. H. El-Sheikh, and G. M. Walker, "Effect of solution pH, ionic strength, and temperature on adsorption behavior of reactive dyes on activated carbon," Dyes and Pigments, vol. 77, pp. 16-23, 2008.

[30] G. de la Puente, J. J. Pis, J. A. Menendez, and P. Grange, "Thermal stability of oxygenated functions in activated carbons," Journal of Analytical and Applied Pyrolysis, vol. 43, pp. 125-138, 1997. 
